\title{
1H-Tetrazole as Catalyst in Phosphomorpholidate Coupling Reactions: Efficient Synthesis of GDP-F ucose, GDP-Mannose, and UDP-Galactose
}

\author{
Valentin Wittmann and Chi-Huey Wong* \\ The Scripps Research Institute, Department of Chemistry, 10550 North Torrey Pines Road, \\ La J olla, California 92037
}

Received October 28, $1996^{\otimes}$

\begin{abstract}
An improved procedure is described for the efficient and high-yield (76-91\%) synthesis of nucleoside diphosphate sugars from the readily available nucleoside 5'-monophosphomor pholidate and sugar 1-phosphate in the presence of $1 \mathrm{H}$-tetrazole. Comparative kinetic investigations by means of ${ }^{31} \mathrm{P}$ NMR spectroscopy with different additives (1,2,4-triazole, acetic acid, N-hydroxysuccinimide, 4-(dimethylamino)pyridine hydrochloride, perchloric acid) and mass spectrometric analysis suggest that tetrazole acts as an acid and as a nucleophilic catalyst in the pyrophosphate bond formation.
\end{abstract}

Complex carbohydrates and their conjugates are involved in various types of biochemical recognition processes. ${ }^{1}$ Glycosyltransferase-catalyzed synthesis of these important structures is attractive since these reactions proceed regio- and stereoselectively in aqueous media without requiring complicated manipulations of protecting groups. ${ }^{2,3}$ As glycosyl donors, the glycosyltransferases of the Leloir pathway ${ }^{4,5}$ in mammalian systems employ primarily eight sugar nucleotides: UDP-GIc, UDPGIcNAc, UDP-Gal, UDP-GalNAc, GDP-Man, GDP-Fuc, UDP-GICUA, and CMP-NeuAC. For an efficient use of glycosyltransferases in the synthesis of ol igosaccharides a practicable (high yield) preparation of these cosubstrates is demanded.

Most of the chemical syntheses of sugar diphosphate nucleosides ${ }^{6,7}$ involve the coupling of a glycosyl phosphate $\mathbf{1}$ with an activated nucleoside monophosphate (NMP) (Scheme 1)..$^{8-14}$ Of the commonly used activated NMP derivatives, phosphoramidates such as phosphorimidazolidates $^{8-10}$ and especially phosphomorpholidates $2^{11-14}$ are the most popular, the latter being introduced in 1959 by Moffatt and Khorana. ${ }^{15,16}$ N evertheless, the reaction between a sugar 1-phosphate and an NMP-morpholidate is very slow (reaction times of 5 days are usual), and yields rarely exeed $70 \%$. GDP-Fuc, in particular, is

* To whom correspondence should be addressed. Tel.: (619) 7842487. Fax: (619) 784-2409. E-mail: Wong@scripps.edu.

$\otimes$ Abstract published in Advance ACS Abstracts, March 1, 1997.

(1) Varki, A. Glycobiology 1993, 3, 97-130.

(2) Wong, C.-H.; Whitesides, G. M. Enzymes in Synthetic Organic Chemistry; Pergamon: Oxford, 1994.

(3) Wong, C.-H.; Halcomb, R. L.; I chikawa, Y.; Kajimoto, T. Angew. Chem., Int. Ed. Engl. 1995, 34, 521-546.

(4) Leloir, L. F. Science 1971, 172, 1299-1303. 664.

(5) Kornfeld, R.; Kornfeld, S. Annu. Rev. Biochem. 1985, 54, 631-

(6) Heidlas, J . E.; Williams, K. W.; Whitesides, G. M. Acc. Chem. Res. 1992, 25, 307-314.

(7) Kochetkov, N. K.: Shibaev, V. N. Adv. Carbohydr. Chem Biochem. 1973, 28, 307-399.

(8) Cramer, F.; Neunhoeffer, H. Chem. Ber. 1962, 95, 1664-1669.

(9) Hoard, D. E.; Ott, D. G. J . Am. Chem. Soc. 1965, 87, 1785-1788.

(10) Simon, E. S.; Grabowski, S.; Whitesides, G. M. J . Org. Chem.

1990, 55, 1834-1841.

(11) Moffatt, J. G. Methods Enzymol. 1966, 8, 136-142.

(12) Roseman, S.; Distler, J . J .; Moffatt, J . G.; Khorana, H. G. J . Am. Chem. Soc. 1961, 83, 659-663.

(13) Clark, V. M.; Hutchinson, D. W.; Kirby, A. J .; Warren, S. G. Angew. Chem. 1964, 76, 704-712.

(14) Scheit, K. H. Nucleotides Analogs, Synthesis and Biological Function; Wiley: New York, 1980.

(15) Moffatt, J . G.; Khorana, H. G. J . Am. Chem. Soc. 1959, 81, 1265. 658.

(16) Moffatt, J. G.; Khorana, H. G. J . Am. Chem. Soc. 1961, 83, 649-

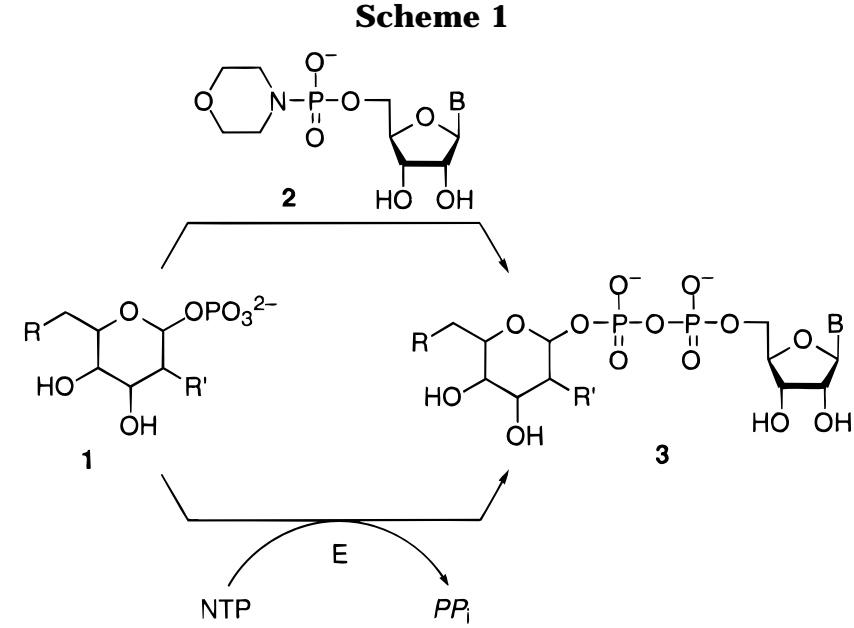

NTP: Nucleoside triphosphate

E: Nucleoside diphosphate sugar pyrophosphorylase

obtained in only $20-50 \%$ yield. ${ }^{17-22}$ Recently, a new approach, involving the reaction of glycosyl bromides with UDP and GDP, was reported. ${ }^{23}$ In the enzymatic preparation of sugar diphosphate nucleosides, a glycosyl phosphate is reacted with a nucleoside triphosphate (NTP), catalyzed by a nucleoside diphosphate sugar pyrophosphorylase (Scheme 1). ${ }^{10,24-29}$ The NTP may also be generated in situ in coupled enzyme reactions. In the case of GDP-Fuc, the enzymatic preparation has been

(17) Nunez, H. A.; O'Connor, J . V.; Rosevear, P. R.; Barker, R. Can. J . Chem. 1981, 59, 2086-2095.

(18) Gokhale, U. B.; Hindsgaul, O.; Palcic, M. M. Can. J . Chem. 1990, 68, 1063-1071.

(19) Schmidt, R. R.; Wegmann, B.; J ung, K.-H. Liebigs Ann. Chem. 1991, 121-124.

(20) Veeneman, G. H.; Broxterman, H. J . G.; Marel, G. A. v. d. Boom, J . H. v. Tetrahedron Lett. 1991, 32, 6175-6178.

(21) I chikawa, Y.; Sim, M. M.; Wong, C.-H. J . Org. Chem. 1992, 57, 2943-2946.

(22) Adelhorst, K.; Whitesides, G. M. Carbohydr. Res. 1993, 242, $69-76$.

(23) Arlt, M.; Hindsgaul, O. J . Org. Chem. 1995, 60, 14-15.

(24) Wong, C.-H.; Haynie, S. L.; Whitesides, G. M. J . Org. Chem. 1982, 47, 5416-5418.

(25) Kawaguchi, K.; Kawai, H.; Tochikura, T. Mehtods Carbohydr Chem. 1980, 8, 261-269.

(26) Tochikura, T.; Kawaguchi, K.; Kawai, H.; Mugibayashi, Y.; Ogata, K. J . Fermentl. Technol. 1968, 46, 970.

(27) Tochikura, T.; Kawai, H.; Tobe, S.; Kawaguchi, K.; Osugi, M.; Ogata, K. J . Fermentl. Technol. 1968, 46, 957.

(28) Korf, U.; Thimm, J .; Thiem, J. Synlett 1991, 313-314.

(29) Ginsburg, V. Adv. Enzymol. 1964, 26, 35. 


\section{Scheme 2}

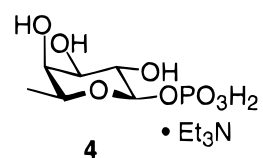

$2(\mathrm{~B}=$ guanine $)$
1 -tetrazole, $\mathrm{pyr}$.
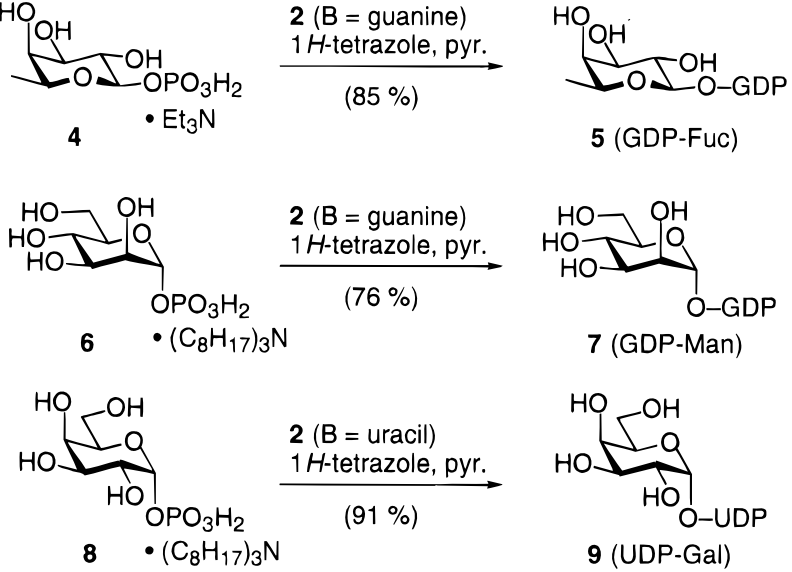

carried out only on an analytical scale. ${ }^{30,31}$ Here, we report the use of $1 \mathrm{H}$-tetrazole as catalyst in phosphomorpholidate coupling reactions, giving rise to shorter reaction times (1-2 days) and higher yields (76-91\%). ${ }^{32}$

\section{Results and Discussion}

The best results for the reaction of a glycosyl phosphate $\mathbf{1}$ in its trialkylammonium form and an NMP-morpholidate $\mathbf{2}$ are usually obtained if the reaction is carried out in pyridine. ${ }^{33}$ However, in the case of GDP-Fuc, even after a reaction time of 5 days, we were able to detect large amaounts of both starting materials, as judged by TLC. As the morpholino group in $\mathbf{2}$ must be protonated before acting as a leaving group and the trialkylammonium counterion of $\mathbf{1}$ (aqueous $\mathrm{pK}_{\mathrm{a}} \mathrm{ca} .10-11$ ) 34 is the only proton source present, we felt that the addition of an acidic catalyst might improve the outcome of the reaction. $1 \mathrm{H}$-Tetrazole $\left(\mathrm{pK}_{\mathrm{a}} 4.9\right)$ is commonly used for the activation of phosphoramidites ${ }^{35,36}$ and accelerates coupling during oligonucleotide synthesis by the phosphotriester method. ${ }^{37,38}$ It turned out that this heterocycle is also an efficient catalyst for the phosphoramidate coupling. Reaction of triethylammonium fucosyl phosphate 4 with guanosine 5'-monophosphomorpholidate (2, $\mathrm{B}=$ guanine) (GMP-morpholidate) and $1 \mathrm{H}$-tetrazole in pyridine was complete after 2 days. Size exclusion chromatography on Bio-Gel P-2, using ammonium bicarbonate solution as eluent, gave spectroscopically pure GDP-Fuc (5) after a single purification step. Under these conditions, an almost complete (>98\%) exchange of the alkylammonium counterions occurred, and $\mathbf{5}$ was obtained as its ammonium salt in $85 \%$ yield. This material was conveniently stored and successfully used in the fucosyltransferase-catalyzed synthesis of sialyl Lewis X.

(30) Ichikawa, Y.; Lin, Y.-C.; Dumas, D. P.; Shen, G.-J .; GarciaJ unceda, E.; Williams, M. A.; Bayer, R.; Ketcham, C.; Walker, L. E.; Paulson, J . C.; Wong, C.-H. J . Am. Chem. Soc. 1992, 114, 9283-9298.

(31) Stiller, R.; Thiem, J . Liebigs Ann. Chem. 1992, 467-471.

(32) A preliminary communication of the use of 1H-tetrazole in phosphoromorpholidate coupling reactions is contained in: Murray, B. W.; Wittmann, V.; Burkart, M. D.; Hung, S.-C.; Wong, C.-H. Biochemistry 1997, 36, 823-831.

(33) Moffatt, J. G.; Khorana, H. G. J . Am. Chem. Soc. 1958, 80, 3756-3761.

(34) All $\mathrm{pK}_{\mathrm{a}}$ data given in this paper correspond to aqueous systems.

(35) Barone, A. D.; Tang, J .-Y.; Caruthers, M. H. Nucl. Acids Res. 1984, 12, 4051-4061.

(36) Sim, M. M., Kondo, H., Wong, C.-H. J . Am. Chem. Soc. 1993 $115,2260-2267$.

(37) Seth, A. K.; J ay, E. Nucleic Acids Res. 1980, 8, 5445-5459.

(38) Zarytova, V. F.; Knorre, D. G. Nucleic Acids Res. 1984, 4, 20912110 and cited references.
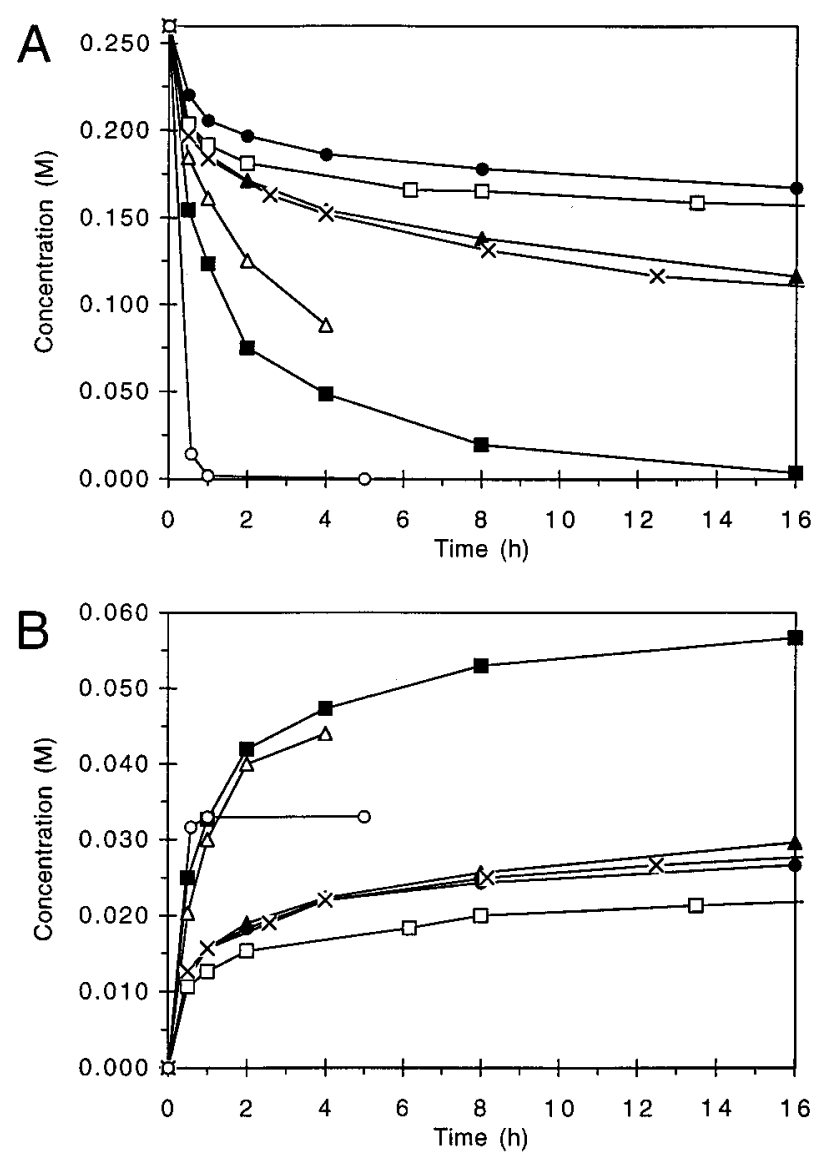

Figure 1. 31P NMR monitoring of (A) GMP-morpholidate and (B) GDP-Fuc (5) during reaction of $\beta$-L-fucopyranosyl phosphate (4) with 1.3 equiv of GMP-morpholidate and 3.2 equiv of an additive in 7:3 pyridine/DMSO-d $\mathrm{d}_{6}:(\bullet)$ no additive; ( $\square$ ) 1,2,4-triazole; $(\mathbf{\Delta})$ acetic acid; $(\times) \mathrm{NHS} ;(\triangle) \mathrm{DMAP} \cdot \mathrm{HCl} ;(\boldsymbol{\square}) \mathrm{1H}$ tetrazole; (O) perchloric acid.

In an analogous manner, mannosyl phosphate (6) and gal actosyl phosphate (8) were converted into GDP-Man (7) $10,12,39$ and UDP-Gal (9) $)^{12,40}$ in 76 and $91 \%$ yield, respectively (Scheme 2). The phosphates $\mathbf{6}$ and $\mathbf{8}$ were used in the trioctylammonium forms, which gave faster reactions than the triethylammonium forms. A common problem in couplings with GMP-morpholidate is its low solubility in pyridine. ${ }^{12}$ Interestingly, addition of tetrazole to a mixture of GMP-morpholidate and pyridine produced a homogeneous solution immediately.

When used to activate phosphoramidites, tetrazole is known to act as both an acid and nucleophilic catalyst, and tetrazolophosphane derivatives have been identified as reactive intermediates. ${ }^{41,42}$ In order to get information about the essential features of tetrazole for activation of phosphomorpholidates, we carried out the coupling reaction with different additives and followed the course of the reaction by ${ }^{31} \mathrm{P}$ NMR spectroscopy (Figure 1). As solvent we used a 7:3 mixture of pyridine and DMSO- $d_{6}$ in order to prevent precipitation of GDP-Fuc or guanosine 5'-monophosphate (GMP). The additives used were $1 \mathrm{H}$ tetrazole, 1,2,4-triazole, acetic acid, N-hydroxysuccinim-

(39) Pallanca, J . E.; Turner, N. J . J . Chem. Soc., Perkin Trans. 1 1993, 3017-3022.

(40) Heidlas, J . E.; Lees, W. J .; Whitesides, G. M. J . Org. Chem. 1992, 57, 152-157.

(41) Dahl, B. H.; Nielsen, J .; Dahl, O. Nucl. Acids Res. 1987, 15, 1729-1743.

(42) Berner, S.; Mühlegger, K.; Seliger, H. Nud. Acids Res. 1989, $17,853-864$ 
ide (NHS), 4-(dimethylamino)pyridine hydrochloride (DMAP. $\mathrm{HCl}$ ), and perchloric adid. Figure $1 \mathrm{~A}, \mathrm{~B}$ shows the decrease of GMP-morpholidate and the increase of GDPFuc, respectively, over time. Since the amount of hydrolysis differed in every reaction, the former gives a more realistic picture of the degree of activation of the morpholidate. Although tetrazole and acetic acid $\left(\mathrm{pK}_{\mathrm{a}}\right.$ 4.75) have almost identical $\mathrm{pK}_{\mathrm{a}}$ values, tetrazole accelerates the reaction much more than acetic acid, suggesting a mechanism in addition to simpleacid catalysis, possibly nucleophilic catalysis. On the other hand, 1,2,4-triazole $\left(\mathrm{pK}_{\mathrm{a}}\right.$ 10.0), which is a stronger nucleophile in pyridine than tetrazole, ${ }^{43}$ has only little effect on the reaction rate compared with the uncatalyzed coupling. The addition of a nucleophile alone is obviously not sufficient; a proton source is also needed. DMAP is a widely used hypernucleophilic acylation catalyst. When applied as its hydrochloride ( $\left.\mathrm{pK}_{\mathrm{a}} 6.1\right)$, it is almost as effective as tetrazole, but due to its restricted solubility in the reaction medium its practical importance is rather low. NHS $\left(\mathrm{pK}_{a} 6.1\right)$ shows the same acceleration as acetic acid, suggesting some enhancement due to nucleophilic catalysis, but it is not as efficient as the equally acidic DMAP.HCl. By far the most strongly activating acid is perchloric acid. Since perchlorate is a poor nucleophile, we conclude that acid alone is sufficient for activating the morpholidate. However, in addition to GDP-F uc large amounts of GMP were also formed, resulting in a lower yield of GDP-Fuc than in the case with tetrazole. Addition of powdered 4 $\AA$ molecular sieves (Aldrich) (which react markedly as base in an aqueous suspension) strongly inhibits the coupling reaction even in the presence of tetrazole. From these findings, we conclude that tetrazole activates GMPmorpholidate by protonation of the leaving group nitrogen and presumably by nucleophilic catalysis via the highly reactive phosphotetrazolide $\mathbf{1 0}$, which reacts with fucosyl phosphate $\mathbf{4}$ to GDP-F uc (5).

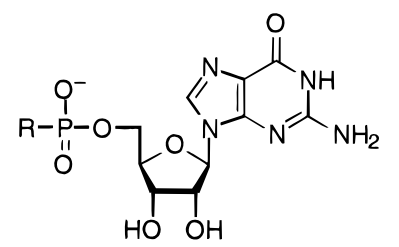

$$
\begin{aligned}
\text { 10: } R=N_{N}^{N}=N-(M=414) \\
\text { 11: } R=\text { MeO } \\
\text { 12: } \mathrm{R}=\text { EtO }
\end{aligned}
$$

In accordance with the proposed intermediate $\mathbf{1 0}$ was the observation of a new resonance at $\delta-12.2 \mathrm{ppm}^{44}$ in a ${ }^{31 P}$ NMR spectrum from a solution of GMP-morpholidate in pyridine/DMSO- $\mathrm{d}_{6}(7: 3) 10 \mathrm{~min}$ after addition of 2 equiv of tetrazole. The integral of this signal corresponded to $4 \%$ of used morpholidate. When treated with excess of methanol or ethanol, this signal disappeared immediately and new resonances at -1.4 and $-1.3 \mathrm{ppm}$, arising from the phosphodiesters $\mathbf{1 1}$ and $\mathbf{1 2}$, respectively, showed up and increased slowly. In addition, we subjected a mixture of GMP-morpholidate and tetrazole in pyridine to mass spectrometric analysis, using electrospray ionization in the negative mode. A spectrum taken after $20 \mathrm{~min}^{45}$ showed, in addition to the peaks of starting material $\left(\mathrm{M}-\mathrm{H}^{+} 431,100\right)$ and hydrolysis product GMP $\left(M-\mathrm{H}^{+} 362,5.3\right)$, a new peak at $\mathrm{m} / \mathrm{z} 414$ (16), consistent with the proposed intermediate 10.

(43) Chandrasegaran, S.; Murakami, A.; Kan, L.-s. J . Org. Chem. 1984, 49, 4951-4957.

(44) A similar chemical shift ( $\delta-11.24 \mathrm{ppm})$ for a comparable phosphotetrazolide has been reported previously. ${ }_{43}$

(45) The mass spectrum was recorded after dilution with dioxane.
In conclusion, we have shown that $1 \mathrm{H}$-tetrazole is an efficient catalyst for phosphomorpholidate coupling reactions. Qualitative kinetic investigations and mass spectrometric analysis suggest a mixture of general acid catalysis and nucleophilic catalysis to be responsible for the rate acceleration. Reaction times are shorter and yields are higher than those reported previously. Since a variety of NMP-morpholidates is commercially available, the tetrazole-activated coupling with glycosyl phosphates provides easy access to sugar nucleotides for subsequent glycosyltransferase-catalyzed glycosylations.

\section{Experimental Section}

General Methods. Anhydrous pyridine was purchased from Aldrich and used without further purification. 4-Morphol ine-N , N'-dicyd ohexylcarboxamidinium guanosine 5'-monophosphomorpholidate, 4-morpholine-N,N'-dicyclohexyl carboxamidinium uridine 5'-monophosphomorpholidate, dipotassium $\alpha$-D-mannosyl phosphate, and dipotassium $\alpha$-D-galactosyl phosphate were purchased from Sigma. For the synthesis of bis(cyclohexylammonium) $\beta$-L-fucopyranosyl phosphate, L-fucose was converted into (2,3,4-tri-O-benzoyl- $\beta$-L-fucopyranosyl) dibenzyl phosphate (three steps, $95 \%$ yield) ${ }^{21}$ and subsequently deprotected (two steps, 87\% yield) 22 according to published procedures. Cation-exchange resin AG 50W-X2 $\mathrm{CH}^{+}$form, strongly acidic) was purchased from Bio-Rad Laboratories and converted to the appropriate salt form prior to its use. When samples were coevaporated with dry pyridine in order to remove residual water, argon was used to bring the pressure back to normal. Analytical thin layer chromatography was performed using silica gel $60 \mathrm{~F}_{254}$ precoated glass plates (Merck); compound spots were visualized by quenching of fluorescence and/or by charring after treatment with cerium molybdophosphate. Size-exclusion chromatography was performed on Bio-Gel P-2 Gel, fine (Bio-Rad Laboratories). ${ }^{31} \mathrm{P}$ NMR spectra were recorded at 162.0 MHz (Bruker AMX-400) and referenced to internal triphenyl phosphine oxide $\left(\delta_{\mathrm{P}}=26.5\right.$ in $7: 3$ pyridine/DMSO- $\left.d_{6}\right)$, which itself was referenced to $85 \%$ $\mathrm{H}_{3} \mathrm{PO}_{4}\left(\delta_{\mathrm{P}}=0.00\right)$ as external standard.

Monoammonium Guanosine 5'-Diphospho- $\beta$-L-fucose (5). Bis(cyclohexylammonium) $\beta$-L-fucopyranosyl phosphate (624 mg, $1.41 \mathrm{mmol}$ ) was dissolved in $\mathrm{H}_{2} \mathrm{O}(15 \mathrm{~mL})$, applied to a Bio-Rad AG 50W-X2 cation-exchange column $\left(\mathrm{Et}_{3} \mathrm{~N}^{+}, 2.5 \times\right.$ $8 \mathrm{~cm})$, and eluted with $\mathrm{H}_{2} \mathrm{O}(150 \mathrm{~mL})$. The solution was evaporated, coevaporated with $\mathrm{MeOH}(2 \times 10 \mathrm{~mL})$, and dried for $3 \mathrm{~d}$ under vacuum to give triethylammonium $\beta$-L-fucopyranosyl phosphate (4) (512 mg). The content of triethylamine was determined to be 1.16 equiv ( $\left.{ }^{1} \mathrm{H} N M R\right)$.

A mixture of $\mathbf{4}(57.5 \mathrm{mg}, 159 \mu \mathrm{mol})$ and 4-morpholine-N, $\mathrm{N}^{\prime}-$ dicyclohexyl carboxamidini um guanosine 5'-monophosphomorpholidate $(201 \mathrm{mg}, 255 \mu \mathrm{mol})$ was coevaporated with dry pyridine $(3 \times 1.5 \mathrm{~mL})$. $1 \mathrm{H}$-Tetrazole $(33 \mathrm{mg}, 477 \mu \mathrm{mol})$ and dry pyridine $(0.8 \mathrm{~mL})$ were added, and the sol ution was stirred at rt. After a while, product started to precipitate. The reaction was monitored by TLC (2:1 i-PrOH/1 M NH$\left.{ }_{4} \mathrm{OAC}\right)$. After $2 \mathrm{~d}$, the mixture was diluted with water $(1.5 \mathrm{~mL})$ to become a clear solution, evaporated, and coevaporated with water $(2 \times 1.5 \mathrm{~mL})$. The residue was purified on a Bio-Gel P-2 column $(2.5 \times 70 \mathrm{~cm})$, eluted with $250 \mathrm{mM} \mathrm{NH} \mathrm{HCO}_{3}$, to give 5 (82.4 $\mathrm{mg}, 85 \%)$ as a white solid after lyophilization $\left(\mathrm{R}_{\mathrm{f}} 0.43,2: 1 \mathrm{i}-\mathrm{PrOH} / 1 \mathrm{M} \mathrm{NH}_{4} \mathrm{OAC}\right)$. The ${ }^{1} \mathrm{H}$ NMR spectral data were in agreement with those published. ${ }^{17,18}$

Monoammonium Guanosine 5'-Diphospho- $\alpha$-D-mannose (7). Dipotassium $\alpha$-D-mannosyl phosphate (110 mg, 311 $\mu \mathrm{mol})$ was dissolved in $\mathrm{H}_{2} \mathrm{O}(1 \mathrm{~mL})$ and passed through a BioRad AG 50W-X2 cation-exchange column (pyridinium form, $1.5 \times 5 \mathrm{~cm})$. The solution was concentrated to a volume of 5 $\mathrm{mL}$, and pyridine $(15 \mathrm{~mL})$ and tri-n-octylamine $(136 \mu \mathrm{L}, 311$ $\mu \mathrm{mol}$ ) were added. The mixture was evaporated and coevaporated with dry pyridine $(3 \times 1.5 \mathrm{~mL})$.

4-Morpholine-N,N'-dicyclohexylcarboxamidinium guanosine 5'-monophosphomorpholidate (392 mg, $497 \mu \mathrm{mol}$ ) was added, and the mixture was coevaporated with dry pyridine $(3 \times 1.5$ 
$\mathrm{mL}$ ). $1 \mathrm{H}$-Tetrazole (70 mg, $994 \mu \mathrm{mol}$ ) and dry pyridine (1.55 $\mathrm{mL}$ ) were added, and the solution was stirred at rt. The reaction was monitored by TLC (2:1 i-PrOH/1 $\left.\mathrm{M} \mathrm{NH}_{4} \mathrm{OAC}\right)$. After $2 \mathrm{~d}$, the mixture was diluted with water $(2 \mathrm{~mL})$ and evaporated. The residue was suspended in $100 \mathrm{mM} \mathrm{NH}{ }_{4} \mathrm{HCO}_{3}$ and extracted with ether to remove the trioctylamine. After evaporation, the residue was purified on a Bio-Gel P-2 col umn $(2.5 \times 95 \mathrm{~cm})$, eluted with $250 \mathrm{mM} \mathrm{NH}_{4} \mathrm{HCO}_{3}$, lyophilized, and precipitated from $\mathrm{H}_{2} \mathrm{O} / \mathrm{MeOH}(1: 2)$ by addition of acetone to give 7 (147 mg, 76\%) as a white solid after lyophilization $\left(R_{f}\right.$ 0.31, 2:1 i-PrOH/1 M NH${ }_{4} \mathrm{OAc}$ ). The ${ }^{1} \mathrm{H}$ NMR spectral data were in agreement with those published. ${ }^{39}$

Monoammonium Uridine 5'-Diphospho- $\alpha$-D-galactose (9). Dipotassium $\alpha$-D-galactosyl phosphate, containing $5.5 \mathrm{~mol}$ of $\mathrm{H}_{2} \mathrm{O}$ (110 mg, $253 \mu \mathrm{mol}$ ), was converted into the trioctylammonium salt using $110 \mu \mathrm{L}(253 \mu \mathrm{mol})$ trioctylamine and reacted with 4-morpholine-N, $\mathrm{N}^{\prime}$-dicycl ohexylcarboxamidinium uridine 5'-monophosphomorpholidate ( $296 \mathrm{mg}, 404 \mu \mathrm{mol})$ and $1 \mathrm{H}$-tetrazole $(57 \mathrm{mg}, 808 \mu \mathrm{mol})$ in dry pyridine $(1.25 \mathrm{~mL})$ as described for 7. Purification on a Bio-Gel P-2 column $(2.5 \times$

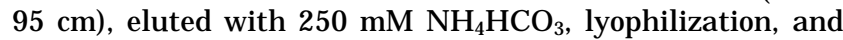
precipitation from $\mathrm{H}_{2} \mathrm{O} / \mathrm{MeOH}$ (1:2) by addition of acetone gave 9 (134 $\mathrm{mg}, 91 \%)$ as a white solid after lyophilization $\left(R_{f} 0.40\right.$, 2:1 i-PrOH/1 M NH${ }_{4} \mathrm{OAC}$ ). The ${ }^{1} \mathrm{H}$ NMR spectral data were in agreement with those published. ${ }^{40}$

31P NMR Spectroscopical Monitoring of Morpholidate Couplings. 4-M orpholine-N, $\mathrm{N}^{\prime}$-dicycl ohexylcarboxamidinium guanosine 5'-monophosphomorpholidate (1.01 g, $1.28 \mathrm{mmol}$ ) and internal standard triphenyl phosphine oxide ( $44.5 \mathrm{mg}, 160$ $\mu \mathrm{mol}$ ) were coevaporated with dry pyridine $(4 \times 5 \mathrm{~mL})$, dried under vacuum for $2 \mathrm{~d}$, and dissolved in pyridine/DMSO- $\mathrm{d}_{6}$ ( 7 : $3,3.9 \mathrm{~mL}$ ). This stock solution was the same for all of the following reactions. Triethylammonium $\beta$-L-fucopyranosyl phosphate (4) (36.2 mg, $100 \mu \mathrm{mol})$ was coevaporated with dry pyridine $(3 \times 1.5 \mathrm{~mL})$ and dried under vacuum for $2 \mathrm{~d}$. GMPmorpholidate stock solution $(500 \mu \mathrm{L})$ and 3.2 equiv $(320 \mu \mathrm{mol})$ of the additive, i.e., $1 \mathrm{H}$-tetrazole ( $22 \mathrm{mg}), 1,2,4$-triazole ( $22 \mathrm{mg})$, acetic acid $(18 \mu \mathrm{L}), \mathrm{NHS}(37 \mathrm{mg}), \mathrm{DMAP} \cdot \mathrm{HCl}(51 \mathrm{mg})$, or anhydrous $\mathrm{HClO}_{4}(19 \mu \mathrm{L})$, respectively, were added. The resulting solution was transferred into a 5-mm NMR tube via syringe, and the reaction was followed by proton-coupled ${ }^{31} \mathrm{P}$ NMR spectroscopy using a pulse angle of $60^{\circ}$ and a relaxation delay of $5 \mathrm{~s}$. Collection of 64 transients gave adequate spectra. Signals at $\delta 4.95$ (GMP-morpholidate), 0.29 (GMP), -0.73 (4), and $-13.38 \mathrm{ppm}(5)^{46}$ were integrated and referenced to the integral of internal standard triphenylphosphine oxide, whose concentration was assumed to stay constant.

Acknowledgment. This work was kindly supported by the NSF. V.W. acknowledges a fellowship from the Deutsche F orschungsgemeinschaft.

\section{J 09620066}

(46) Chemical shifts refer to the uncatalyzed reaction. Slightly different values were observed with each additive. 